\title{
Si Quantum Dots Assist Synthesized Microflower-Like Si/MoS 2 Composites for Supercapacitors
}

\author{
Jiahong Zheng ${ }^{1,2, *}$, Kangkang Cheng ${ }^{1, *}$, Runmei Zhang ${ }^{1}$, Yamei Yang ${ }^{1}$, Yuntao $\mathrm{Wu}^{1}$ and \\ Pengfei Yu ${ }^{1}$ D \\ 1 School of Materials Science and Engineering, Chang'an University, Xi'an 710064, China; \\ zrm199307012222@163.com (R.Z.); 2019131034@chd.edu.cn (Y.Y.); kilo980112@gmail.com (Y.W.); \\ yupengfei@chd.edu.cn (P.Y.) \\ 2 Engineering Research Central of Pavement Materials, Ministry of Education, Chang'an University, \\ Xi'an 710064, China \\ * Correspondence: jhzheng@chd.edu.cn (J.Z.); 2018231026@chd.edu.cn (K.C.); Tel.: +86-029-8233-7340 (J.Z.)
}

Received: 15 August 2020; Accepted: 20 September 2020; Published: 22 September 2020

\begin{abstract}
The microflower-like Si/MoS 2 composites were fabricated using Si quantum dots (QDs) to assist a facile hydrothermal method. The electrochemical performance of Si/MoS 2 composite in symmetric and asymmetric systems was studied. Electrochemical characterization revealed that the $\mathrm{Si} / \mathrm{MoS}_{2}$ composite electrode in a three-electrode system has a high specific capacitance of $574.4 \mathrm{~F} \cdot \mathrm{g}^{-1}$ at $5 \mathrm{~A} \cdot \mathrm{g}^{-1}$. Furthermore, the $\mathrm{Si} / \mathrm{MoS}_{2}$ composite electrode in a two-electrode system had the maximum energy density of $27.2 \mathrm{Wh} \cdot \mathrm{kg}^{-1}$ when a power density of $749.1 \mathrm{~W} \cdot \mathrm{kg}^{-1}$ was achieved. Therefore, this investigation proves the $\mathrm{Si} / \mathrm{MoS}_{2}$ composite microflower-like structure should be a promising candidate electrode material for supercapacitors.
\end{abstract}

Keywords: $\mathrm{Si} / \mathrm{MoS}_{2}$; electrochemical performance; supercapacitor

\section{Introduction}

The progress of science and technology has brought about rapid changes to human life, but has also brought about irreversible problems, such as global warming, the near exhaustion of non-renewable energy, and environmental pollution. Humans are eager to seek new, green energy to alleviate the energy crisis and environmental crisis, and even replace the traditional non-renewable energy [1-3]. Clean energy storage devices have been widely researched, due to their wider and wider application in numerous electronic devices. As a new type of clean energy storage device, supercapacitors have high power density, good cyclic stability, fast charge, and high rate of discharge [4-8].

Nowadays, two-dimensional (2D) materials have shown many unique advantages. Firstly, because electrons are confined to the 2D plane, especially for monolayer 2D materials, their electronic properties are enhanced. Therefore, 2D materials are ideal materials for basic research in condensed matter physics and electronic/optoelectronic devices. Secondly, because 2D materials can maintain the thickness of atoms while possessing the maximum plane size, they have a large specific surface area. This property has greatly attracted research into applications concerning surface area, such as catalysis and supercapacitors. Thirdly, ultra-thin 2D nanomaterials based on liquid phase processing can be prepared by simple methods into a single high-quality film, which is very necessary for practical applications, such as supercapacitors and solar cells.

2D transition metal disulfides (TMDs) have attracted widespread attention, due to their special layer structure. They have better performance of conductivity and larger surface area than oxide, the metal element and sulfur element through the weak van der Waals force of interaction between a 
single layer, forming a similar graphene layer structure [9]. This structure facilitates the insertion and extraction of various ions, and can be developed in the field of energy storage, including for lithium ion batteries and supercapacitors. Transition metal sulfides ( $\mathrm{MoS}_{2}$ [10] CoS [11], NiS [12], CuS [13], etc.) are considered as potential materials for electrodes, because of their wide range of sources, low prices, and unique physicochemical properties. As a representative transition metal sulfide, $\mathrm{MoS}_{2}$ has received extensive attention in capacitor research [14]. Manuraj et al. [15] reported a specific capacitance of $972 \mathrm{~F} \cdot \mathrm{g}^{-1}$ at $1 \mathrm{~A} \cdot \mathrm{g}^{-1}$ for $\mathrm{MoS}_{2}-\mathrm{RuO}_{2}$ nanocomposite. Lien et al. [16] fabricated high voltage symmetric supercapacitors of graphene/ $\mathrm{MoS}_{2}$, which works at a wide operating voltage of $2.3 \mathrm{~V}$ and achieves the maximum energy density of $31.2 \mathrm{Wh} \mathrm{kg}^{-1}$. Vattikuti et al. [17] reported that the hydrothermal reaction synthesized $\mathrm{MoS}_{2} / \mathrm{MoO}_{3}$ heterostructure electrodes have a high specific capacitance of $287.7 \mathrm{~F} \cdot \mathrm{g}^{-1}$ at $1 \mathrm{~A} \cdot \mathrm{g}^{-1}$ with good cycling stability. The $\mathrm{MoS}_{2}$ preparation method is simple and low cost. MoS has different morphologies, such as nanoball [18], nanoflake [19], nanoflower [20], nanofilament [21], nanoparticle [22], etc. It is found that $\mathrm{MoS}_{2}$ can not only show good capacitance in the electrochemical double layer, but can also generate an extra Faraday capacitance, due to the interaction between $\mathrm{Li}^{+}$, $\mathrm{Na}^{+}, \mathrm{K}^{+}$, and other ions inserted into the $\mathrm{MoS}_{2}$ layer. Nevertheless, the energy storage application of pure $\mathrm{MoS}_{2}$ as an electrode material is still very limited, with low conductivity and easy agglomeration, leading to a relatively low capacitance of $\mathrm{MoS}_{2}$. Therefore, the current research focus is to improve the electrochemical performance and increase the capacitance of composite materials

Zero-dimensional semiconductor nanomaterials can be sorted into three categories: IV group quantum dots, III-V group quantum dots [23], and II-VI group quantum dots. In the IV group, $\mathrm{Si}$ is one of the most important elements. Si, one of the most important elements, is the eighth most abundant element in the universe. Si nanomaterials are fully compatible with Si-based microelectronic devices, and nanosilicates have many unusual optical and electrical properties [24]. As a result of high research value, both in the basic theory and practical applications, Si nanomaterials have attracted considerable attention. The quantum confinement effect occurs when the particle size of a Si nanocrystal is reduced to the radius of the exciton Bohr. Si nanocrystals are then called Si QDs. In Si QDs, the motion of electrons or holes in three-dimensional space is constrained by the fact that the constrained carrier can only be located at the separated bound level, and the motion is fully quantized, thus weakening the constraint of momentum conservation. Therefore, the electronic structure of Si semiconductor nanocrystals is different from that of bulk materials of the same composition. It is mainly manifested in the enhancement of electron-hole exchange, the increase of exciton binding energy, and the increase of optical transition oscillation intensity with the decrease of semiconductor gap width. Among the quantum constraint effects, the most reported is the quantum size effect, that is, the band gap increases as the quantum dot size decreases. Si QDs have been developed in recent years with many advantages. The low preparation cost lays a foundation for the rapid application of Si QDs in production. Its low toxicity provides a security guarantee for the experimental research of Si QDs [25]. Its chemical properties provide a basis for the study of its electrochemical properties.

In this article, we propose a scheme for the synthesis of $\mathrm{MoS}_{2}$ using Si QDs to assist hydrothermal synthesis. Using the Si QDs as the center of nucleation promotes the nucleation process of $\mathrm{MoS}_{2}$, and accelerates the reaction speed. $\mathrm{Si} / \mathrm{MoS}_{2}$ composite presents a flower-like structure, with the petals crisscrossing each other. This structure makes the active substance fully contact the electrolyte, which results in the redox reaction. Moreover, to a certain extent, the structure reduces the changes in the microstructure of the material caused by the charging and discharging process. By comparing the electrochemical performance of the two kinds of electrodes $\left(\mathrm{MoS}_{2}\right.$ and $\mathrm{Si} / \mathrm{MoS}_{2}$ composite), the Si/MoS composite electrode demonstrates excellent performance, including high specific capacitance and good cyclic stability. This work can arouse wide interest in the preparation of high-performance mixed-metal sulfide electrode materials by a simple method. 


\section{Materials and Methods}

A total of $0.1 \mathrm{~g}$ of sodium ascorbate was dissolved in $10 \mathrm{~mL}$ deionized (DI) water while stirring for $30 \mathrm{~min}$, then, a solution could be obtained. Following this, $3.75 \mathrm{~mL}$ of sodium ascorbate solution, $1 \mathrm{~mL}$ of N-aminoethyl- $\gamma$-aminopropyltrimethoxysilane, and $12 \mathrm{~mL}$ DI water were mixed with magnetic stirring for $20 \mathrm{~min}$ to obtain a $\mathrm{Si}$ quantum dot solution.

Firstly, $0.7062 \mathrm{~g}\left(\mathrm{NH}_{4}\right)_{6} \mathrm{Mo}_{7} \mathrm{O}_{24} \cdot 6 \mathrm{H}_{2} \mathrm{O}$ and $1.3049 \mathrm{~g} \mathrm{H}_{2} \mathrm{NCSNH}_{2}$ were diluted with $20 \mathrm{~mL}$ DI water. The prepared solution was mixed with $1 \mathrm{~mL} \mathrm{Si} \mathrm{QD} \mathrm{solution,} \mathrm{and} \mathrm{subjected} \mathrm{to} \mathrm{continuous} \mathrm{magnetic}$ stirring for $1 \mathrm{~h}$. Subsequently, the reaction mixture was kept in a Teflon lined stainless steel autoclave at $180^{\circ} \mathrm{C}$ for $18 \mathrm{~h}$. After that, the final mixture product was filtered, washed with DI water, and dried at $60{ }^{\circ} \mathrm{C}$ in a vacuum oven to obtain the Si/MoS 2 composite. For better comparison, the $\mathrm{MoS}_{2}$ was prepared following the same procedures, but without the Si QDs.

An electrochemical station (CHI 660E, Chenhua, Shanghai, China) was taken to test electrochemical performance in $6 \mathrm{M} \mathrm{KOH}$. The sample was used as the working electrode, with a platinum foil $(2 \mathrm{~cm} \times 2 \mathrm{~cm})$ and a saturated calomel electrode as the counter and the reference electrode, respectively. The specific capacitance of the single electrode was calculated using the equation:

$$
\begin{aligned}
& C=i \Delta t /(S \Delta V) \\
& C=i \Delta t /(m \Delta V)
\end{aligned}
$$

where $C$ is the specific capacitance, $i$ is the discharge current, $\Delta t$ is the discharge time, $S$ and $m$ are assigned as the area and mass of the electrode material, and $\Delta V$ represents the potential window.

\section{Results}

Fourier transform infrared (FT-IR) spectroscopy (TENSOR II, Bruker, Karlsruhe, Germany) was used to investigate the bonding interaction and functional groups of samples [26]. As shown in Figure 1a, the peak appearing at $590 \mathrm{~cm}^{-1}$ is assigned to the Mo-S vibration [27], the peak at $1010 \mathrm{~cm}^{-1}$ corresponds to the S-O stretching [28], and the peak at $1413 \mathrm{~cm}^{-1}$ is attributed to C-O stretching vibration [29]. For $\mathrm{MoS}_{2}$, the peaks observed at 1132 and $1651 \mathrm{~cm}^{-1}$ are attributed to the $\mathrm{C}-\mathrm{H}$ bending vibration [27] and the existence of $\mathrm{C}=\mathrm{O}$ stretching vibration [30]. For Si/MoS ${ }_{2}$, the absorption peak at $1106 \mathrm{~cm}^{-1}$ is ascribed to the characteristic stretching of the $\mathrm{Si}-\mathrm{O}-\mathrm{Si}$ band [31]. Figure $1 \mathrm{~b}$ gives the XRD pattern for Si/MoS2 composite. The main diffraction peaks of MoS2 at $2 \theta=33.3^{\circ}, 39.2^{\circ}$ and $48.5^{\circ}$ correspond to (101), (103), and (105) reflections, respectively (JCPDS card no. 37-1492). The peak of Si at $2 \theta=58.6^{\circ}$ can be attributed to the (101) plane (JCPDS card no. $47-1186$ ).
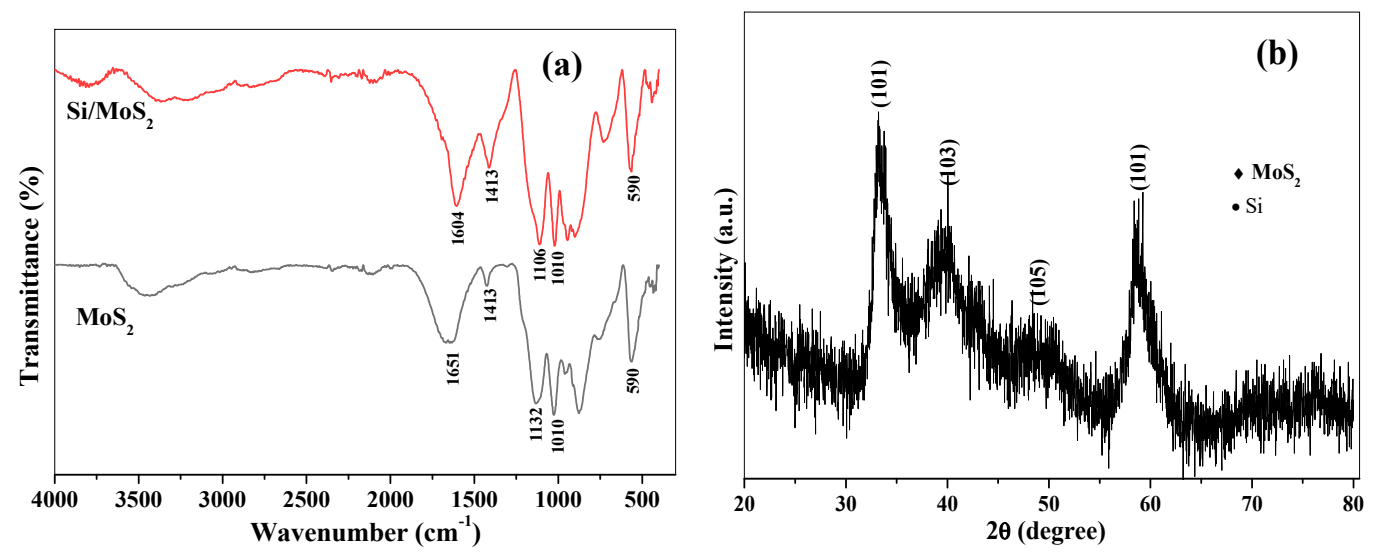

Figure 1. FT-IR spectrum of $\mathrm{MoS}_{2}$ and Si/MoS 2 composite electrodes (a), and XRD pattern of Si/MoS 2 composite (b). 
X-ray photoelectron spectroscopy (XPS, ESCA-LAB Mk II, VG Scientific Co., London, England) was used to analyze the elemental valence state and surface chemical composition. Figure 2 shows the XPS high-resolution spectra of Mo $3 \mathrm{~d}$ and S 2p. The peaks at $230.3 \mathrm{eV}, 233.5 \mathrm{eV}$, and $236.3 \mathrm{eV}$, observed in the pristine spectrum of Mo in Figure $2 \mathrm{a}$, are identified as $\mathrm{Mo}^{4+} 3 \mathrm{~d}_{5 / 2}, \mathrm{Mo}^{4+} 3 \mathrm{~d}_{3 / 2}$, and $\mathrm{Mo}^{6+}$ $3 \mathrm{~d}_{3 / 2}$, respectively [32]. The presence of $\mathrm{Mo}^{6+}$ indicates that there may be a small amount of $\mathrm{MoO}_{3}$ in the sample [33]. Moreover, there is another peak at $227.1 \mathrm{eV}$, which represents $\mathrm{S}^{2-} 2 \mathrm{~s}$ [34]. For S 2p in Figure $2 \mathrm{~b}$, the peaks at $163.7 \mathrm{eV}$ and $164.2 \mathrm{eV}$, observed in the pristine spectrum of $\mathrm{S}$, correspond to $\mathrm{S}$ $2 \mathrm{p}_{5 / 2}$ and $\mathrm{S} 2 \mathrm{p}_{3 / 2}$.
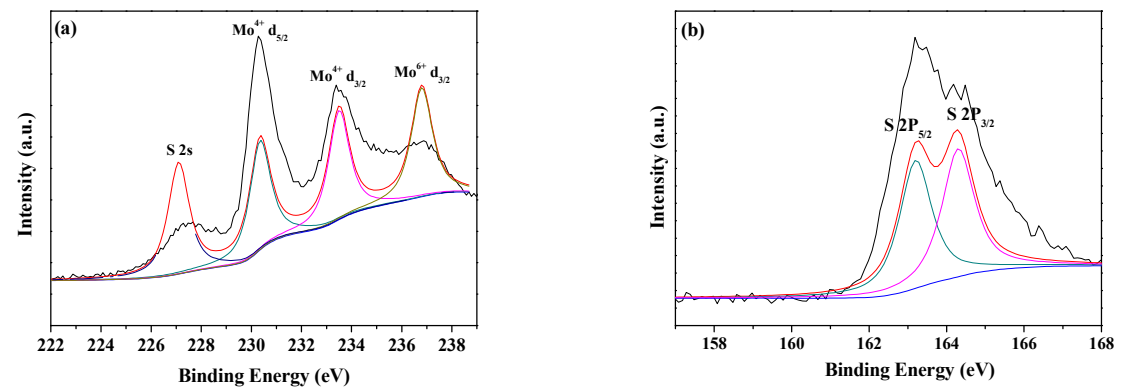

Figure 2. The XPS spectra of (a) the Mo 3d; and (b) the S 2p.

In order to study the effect of Si QDs on the microstructure of the whole composite, field emission scanning electron microscope (FESEM, S-4800, Hitachi, Tokyo, Japan) analysis was used for $\mathrm{MoS}_{2}$ and $\mathrm{Si} / \mathrm{MoS}_{2}$ composite. Figure 3 shows the SEM images of $\mathrm{MoS}_{2}$ and $\mathrm{Si} / \mathrm{MoS}_{2}$ composite. In Figure 3a-c, it can be seen that without $\mathrm{Si}$ QDs, $\mathrm{MoS}_{2}$ is composed of irregular nanosheets with a diameter of 200-300 nm. Most of the nanosheets are tiled, and there are some curled-off phenomena. On the other hand, it still conforms to the rule that $\mathrm{MoS}_{2}$ nanosheets tend to grow in flat under the control of $\mathrm{MoS}_{2}$. Figure 3d,f is the SEM diagram of Si/MoS 2 composite material. After adding a small amount of Si QDs, the $\mathrm{Si} / \mathrm{MoS}_{2}$ composite presents a microflower spherical structure composed of staggered nanosheets, which indicates that the $\mathrm{MoS}_{2}$ nanosheets grow with Si QDs as nucleation centers, and finally grow into three-dimensional flower spheres. The energy dispersive X-ray (EDX) elemental maps in Figure 3g-i reveal that there are $\mathrm{Si}, \mathrm{Mo}$, and $\mathrm{S}$ elements in the $\mathrm{Si} / \mathrm{MoS}_{2}$ composite. It is evident that the $\mathrm{Si}$ QDs are uniformly distributed in $\mathrm{Si} / \mathrm{MoS}_{2}$ composite.

A possible growth mechanism is depicted in the schematic diagram in Figure 4. Without Si QDs, $\mathrm{MoS}_{2}$ tends to grow tiled in the direction with the minimum binding potential energy. With the prolongation of reaction time, the $\mathrm{MoS}_{2}$ nanosheets grew more and more, and were stacked. A small part of $\mathrm{MoS}_{2}$ nanosheets can overcome the crimping of partial binding potential energy or the semi-upright growth. It may be caused by the dynamic force generated by the easy agglomeration of $\mathrm{MoS}_{2}$ itself, which can overcome the crimp growth of certain binding potential energy, and finally form the structure in Figure 3c; when, with Si QDs, due to the small size of Si QDs, it can be used as the nucleation center in the reaction process. The generated $\mathrm{MoS}_{2}$ nanosheet tends to pile up around Si QDs, overcoming the potential energy for rapid three-dimensional growth, and finally forming a micron flower ball. As a result, the structure in Figure $3 \mathrm{f}$ is formed with the continuation of the reaction time. 

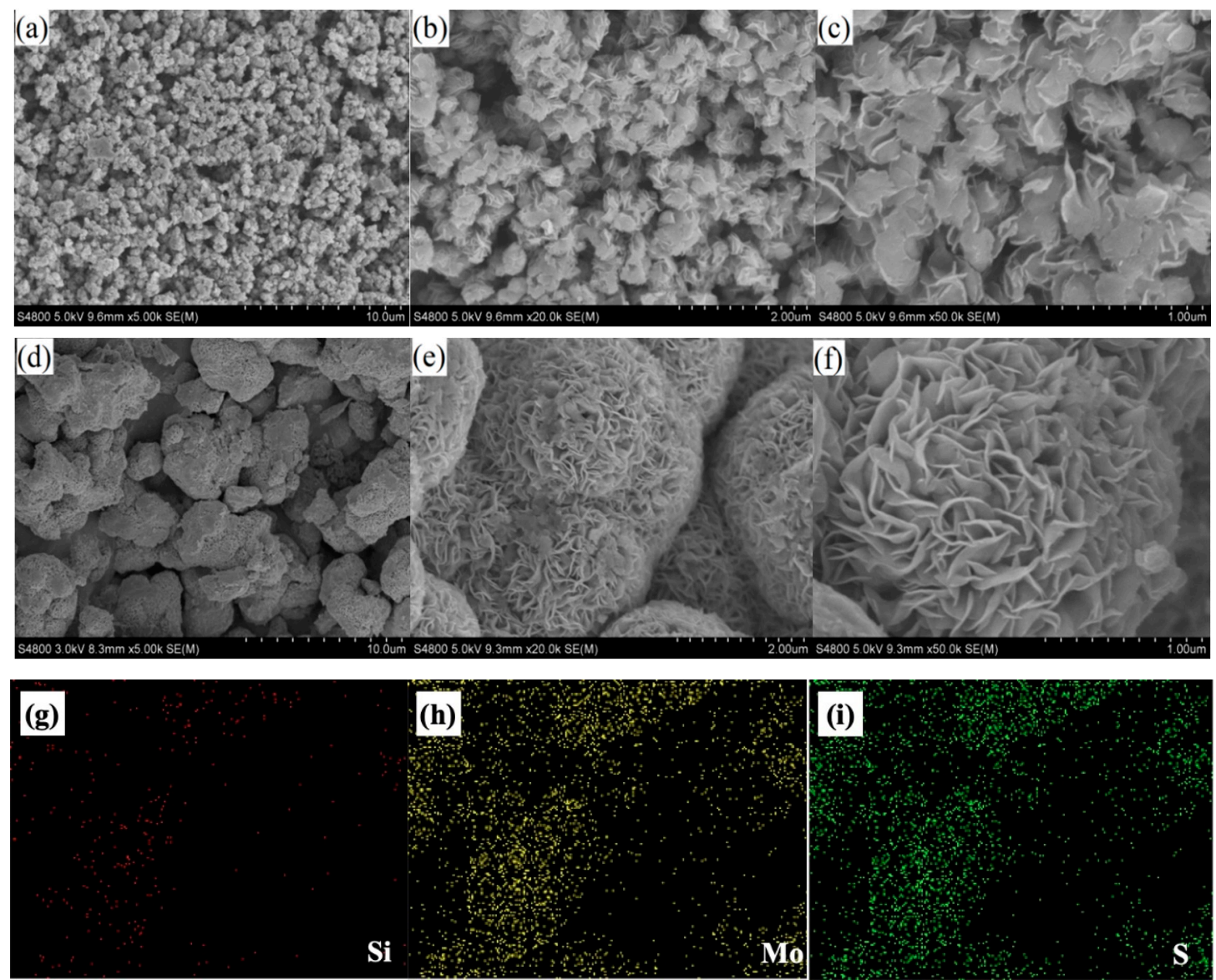

Figure 3. SEM images of $\mathrm{MoS}_{2}(\mathbf{a}-\mathbf{c}), \mathrm{S}$ and Si/MoS 2 composite (d-f), and EDX elemental mapping image of $\mathrm{Si}(\mathbf{g}), \mathrm{Mo}(\mathbf{h})$, and $\mathrm{S}(\mathbf{i})$ in $\mathrm{Si} / \mathrm{MoS} 2$ composite.
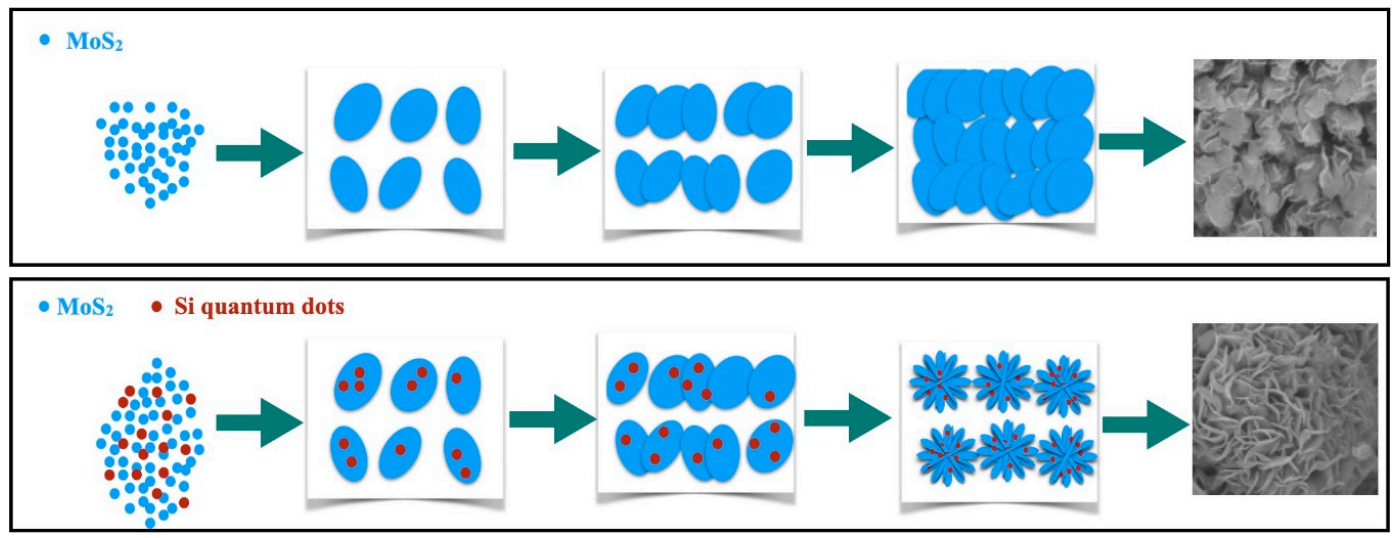

Figure 4. Schematic illustration of the formation for $\mathrm{MoS}_{2}$ and $\mathrm{Si} / \mathrm{MoS}_{2}$ composite.

Figure 5a is the transmission electron microscope (TEM, Tecnai F30G2, FEI, Hillsboro, OR, USA) image of $\mathrm{Si} / \mathrm{MoS}_{2}$. It confirms the microflower structure further, in which many nanosheets are stacked on each other. The result is consistent with the SEM image in Figure 3f. Figure $5 b$ is a high-resolution-TEM image of $\mathrm{Si} / \mathrm{MoS}_{2}$, in which it is clearly observable the ordered lattice fringes with the corresponding interplanar distance of $0.61 \mathrm{~nm}$, which relates to the (002) plane of the $\mathrm{MoS}_{2}$ [35]. Figure $5 c$ is the high-resolution image after the Fourier transform of the box area in Figure $5 b$. The 
crystal lattice of the sample can be observed to be $0.22 \mathrm{~nm}$, which corresponds to the (100) plane of the $\mathrm{MoS}_{2}$.
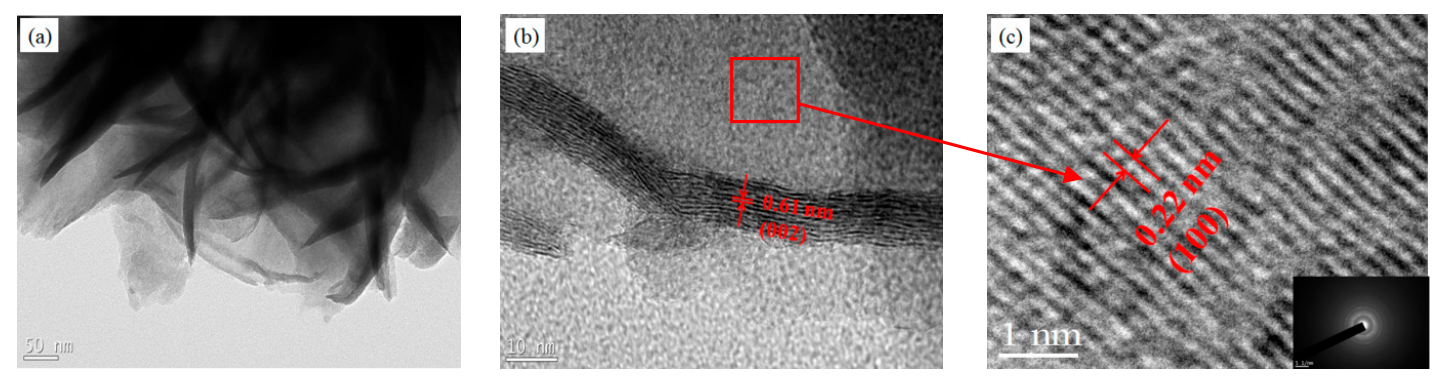

Figure 5. TEM image of Si/MoS 2 composite (a); high-resolution TEM images (b) and (c).

In order to compare the electrochemical properties of the $\mathrm{MoS}_{2}$ and $\mathrm{Si} / \mathrm{MoS}_{2}$ composite, CV curves with a scan rate of $100 \mathrm{mV} \cdot \mathrm{s}^{-1}$ were given in Figure $6 \mathrm{a}, \mathrm{b}$. In Figure $6 \mathrm{a}$, the integral areas of the CV curve of the $\mathrm{Si} / \mathrm{MoS}_{2}$ composite are bigger than those of $\mathrm{MoS}_{2}$, which suggests that the specific capacitance of $\mathrm{Si} / \mathrm{MoS}_{2}$ composite is bigger than the $\mathrm{MoS}_{2}$. The GCD curves of the $\mathrm{MoS}_{2}$ and Si/MoS 2 composite at the same current density of $50 \mathrm{~A} \cdot \mathrm{g}^{-1}$ are shown in Figure $6 \mathrm{~b}$. The plateaus in the GCD curves indicate that the two samples performed pseudocapacitor behaviors [36], which is consistent with the CV results. In Figure $6 \mathrm{~b}, \mathrm{Si} / \mathrm{MoS}_{2}$ composite possesses a longer discharge time than $\mathrm{MoS}_{2}$, which indicates that it has a large specific capacitance. The specific capacitance of $\mathrm{Si} / \mathrm{MoS}_{2}$ composite is higher than that of $\mathrm{MoS}_{2}$ for the following three reasons: (1) after the addition of Si QDs, Si QDs as the nucleation center, play the role of supporting $\mathrm{MoS}_{2}$ nanosheets, which greatly increases the ion transport channel; (2) the porous and open microflower structure of $\mathrm{Si} / \mathrm{MoS}_{2}$ composite, which can shorten the diffusion path of electrons and ions and enhance electrochemical dynamics [37]; and (3) the open space of the Si/MoS composite microflower can act as the robust reservoir for electrolyte ions, supplying sufficient redox reactions for energy storage [38]. The CV curves for $\mathrm{MoS}_{2}$ and Si/MoS 2 composite at different scan rates of $5-100 \mathrm{mV} / \mathrm{s}$ are shown in Figure $6 \mathrm{c}, \mathrm{d}$. With the increase of the scanning rate, the peak of current gradually increased, and the curve shape remained basically unchanged in the CV curves of $\mathrm{MoS}_{2}$ and $\mathrm{Si} / \mathrm{MoS}_{2}$ composite, indicating that the two electrode materials had the potential to provide high power performance. The GCD curves of the $\mathrm{MoS}_{2}$ and Si/MoS 2 composite at different current densities are shown in Figure 6e,f. The specific capacitances of the $\mathrm{MoS}_{2}$ and Si/MoS 2 composite can be calculated on the basis of the GCD curves, and the results are presented in Figure 6g. The specific capacitance of $\mathrm{Si} / \mathrm{MoS}_{2}$ composite at any of the same current densities is higher than that of $\mathrm{MoS}_{2}$. With the increase of current density, the discharge time is shortened continuously, so the specific capacity is also decreased

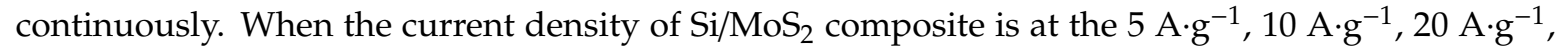
$30 \mathrm{~A} \cdot \mathrm{g}^{-1}, 40 \mathrm{~A} \cdot \mathrm{g}^{-1}$, and $50 \mathrm{~A} \cdot \mathrm{g}^{-1}$, the corresponding specific capacitance of $\mathrm{Si} / \mathrm{MoS}_{2}$ composite electrode is $574.4 \mathrm{~F} \cdot \mathrm{g}^{-1}, 500.0 \mathrm{~F} \cdot \mathrm{g}^{-1}, 404.4 \mathrm{~F} \cdot \mathrm{g}^{-1}, 284.4 \mathrm{~F} \cdot \mathrm{g}^{-1}$, and $233.3 \mathrm{~F} \cdot \mathrm{g}^{-1}$, respectively, which is consistent with the analysis results of $\mathrm{CV}$ curves in Figure $6 \mathrm{c}$,d. Figure $6 \mathrm{i}$ shows cyclic stability of capacitive performance of $\mathrm{Si} / \mathrm{MoS}_{2}$ electrode tested for 1000 cycles at $1 \mathrm{~A} \cdot \mathrm{g}^{-1}$. The $\mathrm{Si} / \mathrm{MoS}_{2}$ composite electrode exhibits specific capacitance retention of $84.5 \%$ for 1000 cycles.

Nyquist plots of the $\mathrm{MoS}_{2}$ and $\mathrm{Si} / \mathrm{MoS}_{2}$ composite electrodes are shown in Figure 6h. Generally, a semicircle in the high frequency region and a straight line with slope in the low frequency region are shown. In the low frequency region, it consists of a straight line, while in the high frequency region, it consists of a semicircle. The diameter of the semicircle is related to the charge transfer resistance (Rct). The radius of the Rct from the high frequency arc is on the real axis. Additionally, the smaller the radius, the smaller the Rct. A smaller Rct for Si/MoS 2 and a vertical line along the virtual axis show lower resistance and better capacitive behavior [39]. The Nyquist curve of the X-ray intercepts the equivalent series resistance of said electrode $\left(R_{S}\right)$, which is $0.506 \Omega$. 

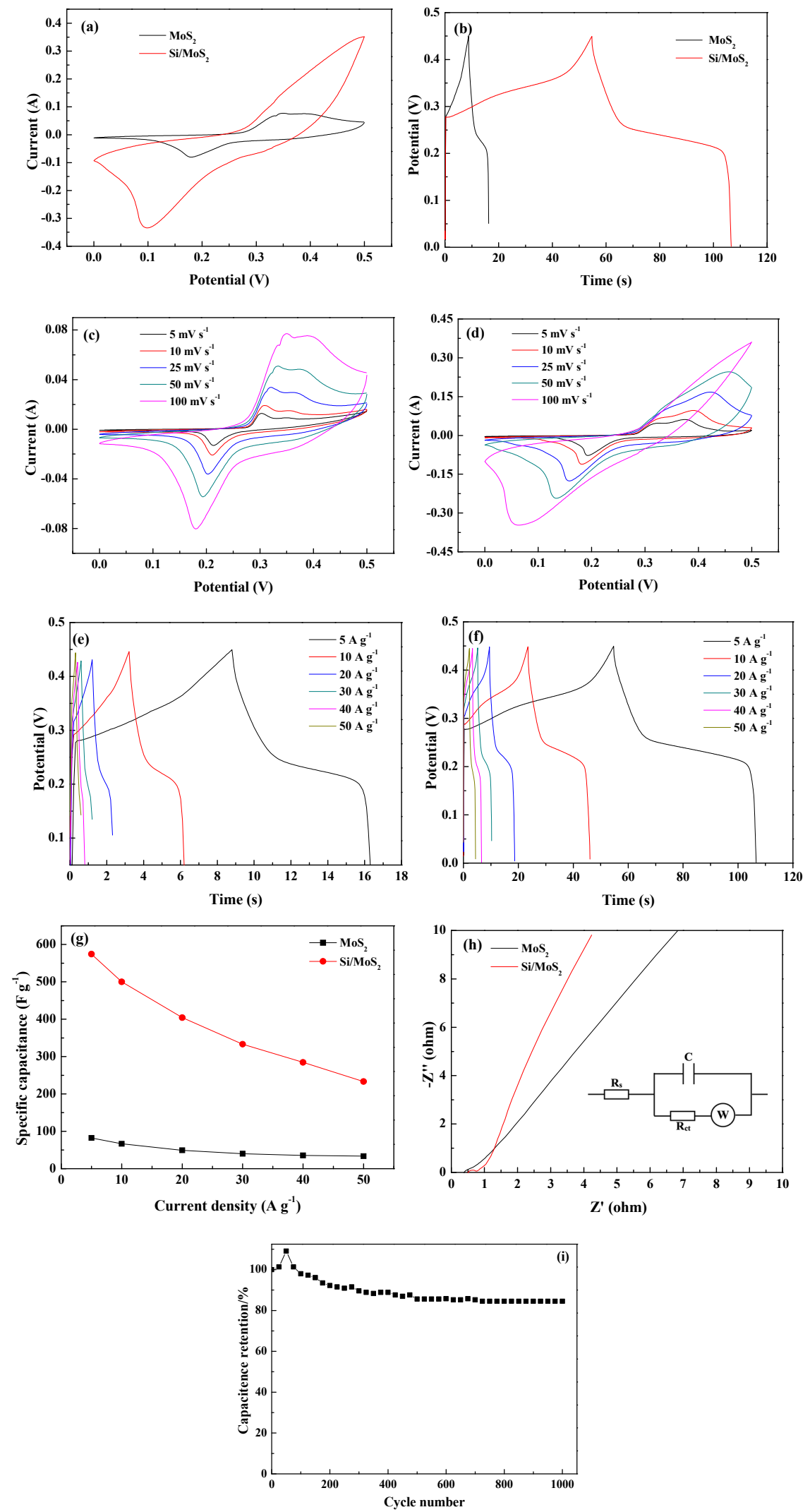

Figure 6. $(\mathbf{a}, \mathbf{b})$ Comparison of CV and GCD curves of two electrodes; (c,e) CV and GCD curves of $\mathrm{MoS}_{2}$ and (d,f) Si/MoS 2 composite; (g) rate capacitance calculated by GCD curves; (h) EIS curves of two electrodes (the inset shows the equivalent circuit model used for fitting the EIS plot); (i) cyclic stability test at $1 \mathrm{~A} \cdot \mathrm{g}^{-1}$ for $\mathrm{Si} / \mathrm{MoS}_{2}$ composite electrode. 
In order to evaluate the potential practical application of the $\mathrm{Si} / \mathrm{MoS}_{2}$ composite electrode, an asymmetric capacitor $\left(\mathrm{Si} / \mathrm{MoS}_{2} / / \mathrm{AC}\right)$ was constructed, with $\mathrm{Si} / \mathrm{MoS}_{2}$ composite active material as positive electrode and $\mathrm{AC}$ as negative electrode, to investigate its electrochemical performance. An electrochemical workstation was used to test the asymmetric supercapacitor electrochemical properties. As shown in Figure 7a, CV curves of the Si/MoS 2 composite and AC separately tested in the three-electrode test system indicated that the optimal potential window of Si/MoS $/ / / \mathrm{AC}$ is $1.5 \mathrm{~V}$, and a good matching for asymmetric supercapacitors. Figure $7 \mathrm{~b}$ shows $\mathrm{CV}$ curves of $\mathrm{Si} / \mathrm{MoS}_{2} / / \mathrm{AC}$ at various scan rates, which show that the pseudocapacitance and double-layer capacitance are common influences on the supercapacitor. The shapes of CV curves were not deformed when the sweep speeds increased, indicating good rate performance. The $C$ (specific capacitance $\left(86.9 \mathrm{~F} \cdot \mathrm{g}^{-1}\right)$ ) in the asymmetric capacitor was calculated based on the Figure 7c discharge curves when current density was at $1 \mathrm{~A} \cdot \mathrm{g}^{-1}$. The Ragone plot is displayed in Figure $7 \mathrm{~d}$. The maximum energy density of $27.2 \mathrm{Wh} \cdot \mathrm{kg}^{-1}$ is obtained at a power density of $749.1 \mathrm{Wh} \cdot \mathrm{kg}^{-1}$, which is more than other reported systems, such as $\mathrm{MoS}_{2}-150 \mathrm{mg}$ GF//AEG $\left(16 \mathrm{Wh} \cdot \mathrm{kg}^{-1} / 758.2 \mathrm{~W} \cdot \mathrm{kg}^{-1}\right)$ [6], BCN/MoS ${ }_{2}-31$ composite $\left(8.92 \mathrm{Wh} \cdot \mathrm{kg}^{-1} / 254.8 \mathrm{~W} \cdot \mathrm{kg}^{-1}\right)$ [40], PANI-G-MoS $2\left(2.65 \mathrm{Wh} \cdot \mathrm{kg}^{-1} / 119.2 \mathrm{~W} \cdot \mathrm{kg}^{-1}\right)$ [41], and $\mathrm{MoS}_{2} / \mathrm{RCF}$ electrode $\left(22.5 \mathrm{Wh} \cdot \mathrm{kg}^{-1} / 703 \mathrm{~W} \cdot \mathrm{kg}^{-1}\right)$ [9].
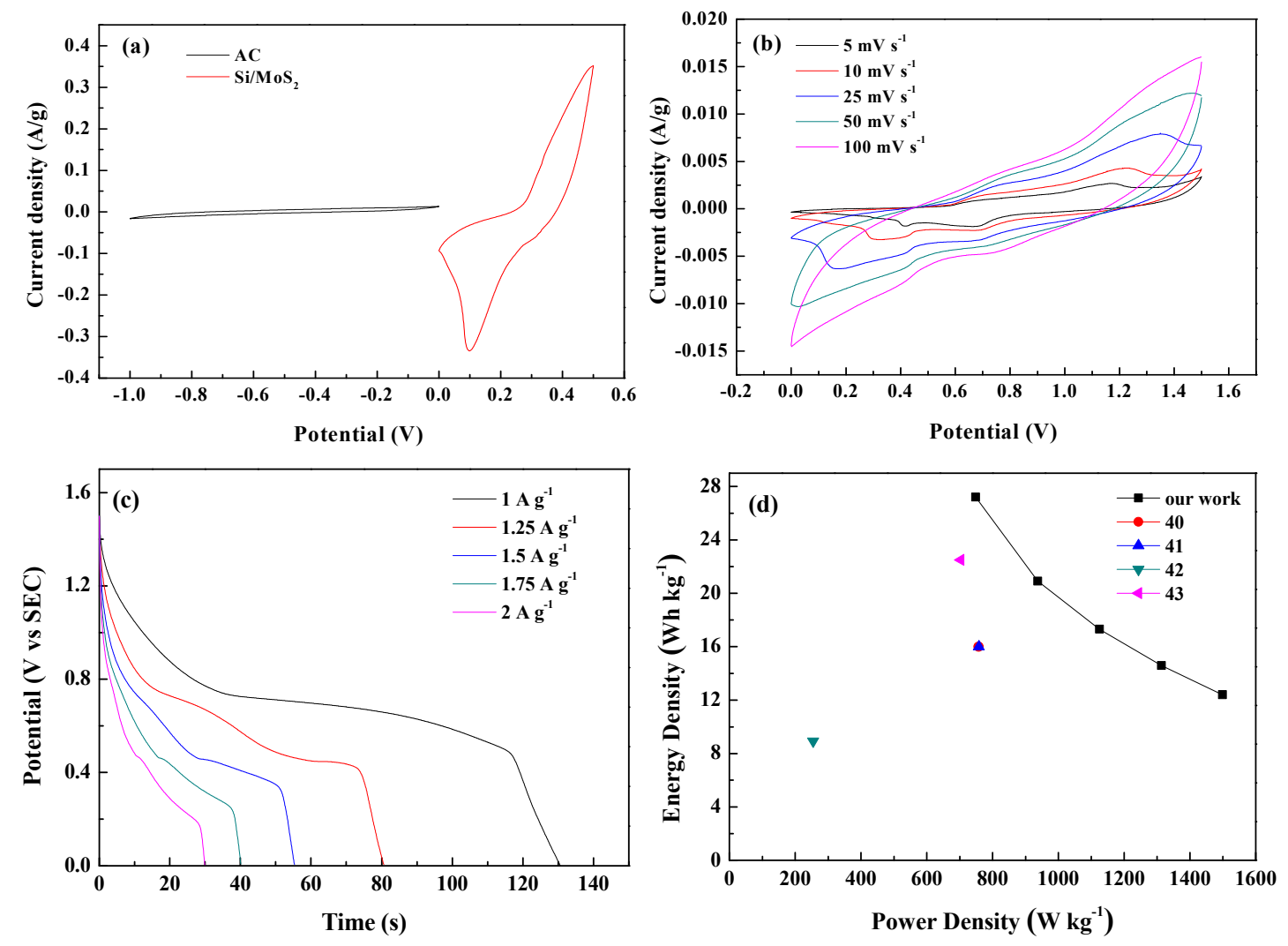

Figure 7. (a) CV curve of $\mathrm{AC}$ and $\mathrm{Si} / \mathrm{MoS}_{2}$ composite, separately tested in three-electrode system at $100 \mathrm{mV} \cdot \mathrm{s}^{-1}$; (b) CV curve of asymmetric supercapacitor (Si/MoS $\left.2 / / \mathrm{AC}\right)$; (c) GCD curve of Si/MoS $2 / / \mathrm{AC}$; (d) Ragone plots of $\mathrm{Si} / \mathrm{MoS}_{2} / / \mathrm{AC}$.

\section{Conclusions}

In this work, microflower-like structure $\mathrm{Si} / \mathrm{MoS}_{2}$ composite was prepared by hydrothermal method. The addition of Si QDs can improve the electrochemical performance of $\mathrm{MoS}_{2}$. The capacitance of the $\mathrm{Si} / \mathrm{MoS}_{2}$ composite is $574.4 \mathrm{~F} \cdot \mathrm{g}^{-1}$ at $5 \mathrm{~A} \cdot \mathrm{g}^{-1}$. When the energy density is $27.2 \mathrm{Wh} \cdot \mathrm{kg}^{-1}$, the power density of the Si/MoS $/ / \mathrm{AC}$ reaches $749.1 \mathrm{~W} \cdot \mathrm{kg}^{-1}$. The capacitance retention is $84.5 \%$, even after 
1000 cycles. Therefore, the Si/MoS 2 composite microflower will be a great potential electrode material for supercapacitors.

Author Contributions: J.Z. and R.Z. conceived and designed the experiments; R.Z. and K.C. fabricated the sample; Y.Y. and Y.W. characterized the sample; P.Y. oversaw project administration. All authors have read and agreed to the published version of the manuscript.

Funding: The work was funded by National Natural Science Foundation of China (Grant No. 21607013, 5102026), the Natural Science Basic Research Plan in Shaanxi Province of China (2020JM-221), the Fund Project of Shaanxi Key Laboratory of Land Consolidation (2018-JC01), the Fundamental Research Funds for the Central Universities, CHD (300102310203), and Colation and Entrepreneurship Project (201810710127, 201910710466).

Conflicts of Interest: The authors declare no conflict of interest.

\section{References}

1. Fu, H.; Zhang, X.D.; Fu, J.Z.; Shen, G.Z.; Ding, Y.L.; Chen, Z.J.; Du, H. Single layers of $\mathrm{MoS}_{2} / \mathrm{Graphene}$ nanosheets embedded in activated carbon nanofibers for high-performance supercapacitor. J. Alloy Compd. 2020, 829, 154557. [CrossRef]

2. Wang, C.; Xu, J.; Yuen, M.; Zhang, J.; Li, Y.; Chen, X.; Zhang, W. Hierarchical composite electrodes of nickel oxide nanoflake 3D graphene for high-performance pseudocapacitors. Adv. Funct. Mater. 2014, 24, 6372-6380. [CrossRef]

3. Reddy, B.P.; Sekhar, M.C.; Vattikuti, S.V.P.; Suh, Y.; Park, S.H. Solution-based spin-coated tin sulfide thin films for photovoltaic and supercapacitor applications. Mater. Res. Bull. 2018, 103, 13-15. [CrossRef]

4. Vikraman, D.; Karuppasamy, K.; Hussain, S.; Kathalingam, A.; Sanmugam, A.; Jung, J.; Kim, H.S. One-pot facile methodology to synthesize $\mathrm{MoS}_{2}$-graphene hybrid nanocomposites for supercapacitors with improved electrochemical capacitance. Compos. Part B Eng. 2019, 161, 555-563. [CrossRef]

5. Vattikuti, S.V.P.; Reddy, B.P.; Byon, C.; Shim, J. Carbon/CuO nanosphere-anchored g- $\mathrm{C}_{3} \mathrm{~N}_{4}$ nanosheets as ternary electrode material for supercapacitors. J. Solid State Chem. 2018, 262, 106. [CrossRef]

6. Masikhwa, T.M.; Madito, M.J.; Bello, A.; Dangbegnon, J.K.; Manyala, N. High performance asymmetric supercapacitor based on molybdenum disulphide/graphene foam and activated carbon from expanded graphite. J. Colloid Interf. Sci. 2017, 488, 155-165. [CrossRef]

7. Yadav, S.K.; Kumar, R.; Sundramoorthy, A.K.; Singh, R.K.; Koo, C.M. Simultaneous reduction and covalent grafting of polythiophene on graphene oxide sheets for excellent capacitance retention. RSC Adv. 2016, 6, 52945-52949. [CrossRef]

8. Vattikuti, S.V.P.; Devarayapalli, K.C.; Nagajyothi, P.C.; Shim, J. Microwave synthesized dry leaf-like mesoporous $\mathrm{MoSe}_{2}$ nanostructure as an efficient catalyst for enhanced hydrogen evolution and supercapacitor applications. Microchem. J. 2020, 153, 104446. [CrossRef]

9. Zhao, C.H.; Zhou, Y.N.; Ge, Z.X.; Zhao, C.G.; Qian, X.Z. Facile construction of $\mathrm{MoS}_{2} / \mathrm{RCF}$ electrode for high-performance supercapacitor. Carbon 2018, 127, 699-706. [CrossRef]

10. Xu, C.Y.; Jiang, L.; Li, X.; Li, C.; Shao, C.X.; Zuo, P.; Liang, M.S.; Qu, L.T.; Cui, T.H. Miniaturized high-performance metallic 1T-Phase MoS2 micro-supercapacitors fabricated by temporally shaped femtosecond pulses. Nano Energy 2020, 67, 104260. [CrossRef]

11. Lia, J.F.; Chen, D.D.; Wu, Q.S. Facile synthesis of CoS porous nanoflake for high performance supercapacitor electrode materials. J. Energy Storage 2019, 23, 511-514. [CrossRef]

12. Harish, S.; Naveen, A.N.; Abinaya, R.; Archana, J.; Ramesh, R.; Navaneethan, M.; Shimomura, M.; Hayakawa, Y. Enhanced performance on capacity retention of hierarchical NiS hexagonal nanoplate for highly stable asymmetric supercapacitor. Electrochim. Acta 2018, 283, 1053-1062. [CrossRef]

13. Himasree, P.; Durga, I.K.; Krishna, T.N.V.; Rao, S.S.; Gopi, C.V.V.M.; Revathi, S.; Prabakar, K.; Kim, H.J. One-step hydrothermal synthesis of CuS@MnS on Ni foam for high performance supercapacitor electrode material. Electrochim. Acta 2019, 305, 467-473. [CrossRef]

14. Kumar, R.; Sahoo, S.; Joanni, E.; Singh, R.K.; Yadav, R.M.; Verma, R.K.; Singh, D.P.; Tan, W.K.; del Pino, A.P.; Moshkalev, S.A.; et al. A review on synthesis of graphene, h-BN and $\mathrm{MoS}_{2}$ for energy storage applications: Recent progress and perspectives. Nano Res. 2019, 12, 2655-2694. [CrossRef]

15. Manuraj, M.; Chacko, J.; Unni, K.N.N.; Rakhi, R.B. Heterostructured $\mathrm{MoS}_{2}-\mathrm{RuO}_{2}$ nanocomposite: A promising electrode material for supercapacitors. J. Alloy Compd. 2020, 836, 155420. [CrossRef] 
16. Lien, C.W.; Vedhanarayanan, B.; Chen, J.H.; Lin, J.Y.; Tsai, H.H.; Shao, L.D.; Lin, T.W. Optimization of acetonitrile/water content in hybrid deep eutectic solvent for graphene/MoS 2 hydrogel-based supercapacitors. Chem. Eng. J. 2021, 405, 126706. [CrossRef]

17. Vattikuti, S.V.P.; Nagajyothi, P.C.; Reddy, P.A.K.; Kumar, M.K.; Shim, J.; Byon, C. Tiny $\mathrm{MoO}_{3}$ nanocrystals self-assembled on folded molybdenum disulfide nanosheets via a hydrothermal method for supercapacitor. Mater. Res. Lett. 2018, 6, 432-439. [CrossRef]

18. Feng, D.; Pan, X.X.; Xia, Q.Y.; Qin, J.H.; Zhang, Y.; Chen, X.M. Metallic $\mathrm{MoS}_{2}$ nanosphere electrode for aqueous symmetric supercapacitors with high energy and power densities. J. Mater. Sci. 2020, 55, 713-723. [CrossRef]

19. Voiry, D.; Salehi, M.; Silva, R.; Fujita, T.; Chen, M.W.; Asefa, T.; Shenoy, V.B.; Eda, G.; Chhowalla, M. Conducting $\mathrm{MoS}_{2}$ Nanosheets as Catalysts for Hydrogen Evolution Reaction. Nano Lett. 2013, 13, 6222-6227. [CrossRef]

20. Mishra, S.; Maurya, P.K.; Mishra, A.K. 2H-MoS 2 nanoflowers based high energy density solid state supercapacitor. Mater. Chem. Phys. 2020, 255, 123551. [CrossRef]

21. Wu, D.; Lou, Z.; Wang, Y.; Yao, Z.; Xu, T.; Shi, Z.; Xu, J.; Tian, Y.; Li, X.; Tsang, Y.H. Photovoltaic high-performance broadband photodetector based on $\mathrm{MoS}_{2} / \mathrm{Si}$ nanowire array heterojunction. Sol. Energ. Mat. Sol. C. 2018, 182, 272-280. [CrossRef]

22. Feng, Z.; Yang, P.P.; Wen, G.S.; Li, H.B.; Liu, Y.; Zhao, X.C. One-step synthesis of $\mathrm{MoS}_{2}$ nanoparticles with different morphologies for electromagnetic wave absorption. Appl. Surf. Sci. 2020, 502, 144129. [CrossRef]

23. Kumar, R.; Singh, R.K.; Yadav, S.K.; Savu, R.; Moshkalev, S.A. Mechanical pressure induced chemical cutting of boron nitride sheets into boron nitride quantum dots and optical properties. J. Alloy. Compd. 2016, 683, 38-47. [CrossRef]

24. Singh, R.K.; Kumar, R.; Singh, D.P.; Savu, R.; Moshkalev, S.A. Progress in microwave-assisted synthesis of quantum dots (graphene/carbon/semiconducting) for bioapplications: A review. Mater. Today Chem. 2019, 12, 282-332. [CrossRef]

25. Erogbogbo, F.; Yong, K.T.; Roy, I.; Hu, R.; Law, W.C.; Zhao, W.W.; Ding, H.; Wu, F.; Kumar, R.; Swihart, M.T.; et al. In vivo targeted cancer imaging, sentinel lymph node mapping and multi-channel imaging with biocompatible silicon nanocrystals. ACS Nano 2011, 5, 413-423. [CrossRef]

26. Arefi-Oskoui, S.; Khataee, A.; Safarpour, M.; Vatanpour, V. Modification of polyethersulfone ultrafiltration membrane using ultrasonicassisted functionalized $\mathrm{MoS}_{2}$ for treatment of oil refinery wastewater. Sep. Purif. Technol. 2020, 238, 116495. [CrossRef]

27. Zhang, X.L.; Ma, L.; Gan, M.Y.; Fu, G.; Jin, M.; Zhai, Y.F. Controllable constructing of hollow MoS $2 / \mathrm{PANI}$ core/shell microsphere for energy storage. Appl. Surf. Sci. 2018, 460, 48-57. [CrossRef]

28. Raza, A.; Ikram, M.; Aqeel, M.; Imran, M.; Ul-Hamid, A.; Riaz, K.N.; Ali, S. Enhanced industrial dye degradation using Co doped in chemically exfoliated $\mathrm{MoS}_{2}$ nanosheets. Appl. Nanosci. 2020, 10, 1535-1539. [CrossRef]

29. Zhong, Y.; Sun, X.; Wang, S.; Peng, F.; Bao, F.; Su, Y.; Li, Y.; Lee, S.T.; He, Y. Facile, Large-Quantity Synthesis of Stable, Tunable-Color Silicon Nanoparticles and Their Application for Long-Term Cellular Imaging. ACS Nano 2015, 9, 5958-5959. [CrossRef]

30. Liu, Z.P.; Hou, J.Z.; Wang, X.F.; Hou, C.J.; Ji, Z.; He, Q.; Huo, D.Q. A novel fluorescence probe for rapid and sensitive detection of tetracyclines residues based on silicon quantum dots. Spectrochim. Acta A 2020, 240, 118463. [CrossRef]

31. Xu, X.X.; Jiao, S.L.; Liu, Z.Q.; Liu, L. Synergistic lubrication of a porous $\mathrm{MoS}_{2}$-POSS nanohybrid. RSC Adv. 2020, 10, 20579. [CrossRef]

32. Yang, Z.M.; Zhang, D.Z.; Chen, H.N. MOF-derived indium oxide hollow microtubes/MoS 2 nanoparticles for $\mathrm{NO}_{2}$ gas sensing. Sensor. Actuat. B Chem. 2019, 300, 127037. [CrossRef]

33. Zhao, P.; Tang, Y.; Mao, J.; Chen, Y.; Song, H.; Wang, J.; Song, Y.; Liang, Y.; Zhang, X. One-dimensional $\mathrm{MoS}_{2}$-decorated $\mathrm{TiO}_{2}$ nanotube gas sensors for efficient alcohol sensing. J. Alloy. Compd. 2016, 674, 252-258. [CrossRef]

34. Zhao, S.; Li, Z.; Wang, G.; Liao, J.; Lv, S.; Zhu, Z. Highly enhanced response of MoS2/porous silicon nanowire heterojunctions to $\mathrm{NO}_{2}$ at room temperature. RSC Adv. 2018, 8, 11070-11077. [CrossRef]

35. Luo, J.H.; Zhang, K.; Cheng, M.L.; Gu, M.M.; Sun, X.K. MoS 2 spheres decorated on hollow porous ZnO microspheres with strong wideb and microwave absorption. Chem. Eng. J. 2020, 380, 122625. [CrossRef]

36. Arasi, S.E.; Ranjithkumar, R.; Devendran, P.; Krishnakumar, M.; Arivarasan, A. Electrochemical evaluation of binary $\mathrm{Ni}_{2} \mathrm{~V}_{2} \mathrm{O}_{7}$ nanorods as pseudocapacitor electrode material. Ceram. Int. 2020, 46, 22709-22717. [CrossRef] 
37. Guan, B.; Li, Y.; Yin, B.Y.; Liu, K.F.; Wang, D.W.; Zhang, H.H.; Cheng, C.J. Synthesis of hierarchical NiS microflower for high performance asymmetric supercapacitor. Chem. Eng. J. 2017, 308, 1165-1173. [CrossRef]

38. Huo, H.H.; Zhao, Y.Q.; $\mathrm{Xu}$, C.L. $3 \mathrm{D} \mathrm{Ni} \mathrm{S}_{2}$ nanosheet arrays supported on $\mathrm{Ni}$ foam for high-performance supercapacitor and nonenzymatic glucose detection. J. Mater. Chem. A 2014, 2, 15111-15117. [CrossRef]

39. Peng, W.J.; Wang, W.; Han, G.H.; Huang, Y.K.; Zhang, Y.S. Fabrication of 3D flower-like MoS $_{2} /$ graphene $^{2}$ composite as highperformance electrode for capacitive deionization. Desalination 2020, 473, 114191. [CrossRef]

40. Thakur, A.K.; Majumder, M.; Choudhary, R.B.; Singh, S.B. MoS 2 flakes integrated with boron and nitrogen-doped carbon: Striking gravimetric and volumetric capacitive performance for supercapacitor applications. J. Power Sources 2018, 402, 163-173. [CrossRef]

41. Palsaniya, S.; Nemade, H.B.; Dasmahapatra, A.K. Synthesis of polyaniline/graphene/MoS 2 nanocomposite for high performance supercapacitor electrode. Polymer 2018, 150, 150-158. [CrossRef]

(C) 2020 by the authors. Licensee MDPI, Basel, Switzerland. This article is an open access article distributed under the terms and conditions of the Creative Commons Attribution (CC BY) license (http://creativecommons.org/licenses/by/4.0/). 